\title{
FORMACุÃO DE MEDIADORES EM MUSEUS DE CIÊNCIA: SABERES E PRÁTICAS
}

RESUMO: A despeito do uso frequente da mediação humana em museus de ciência há pouco investimento na formação de profissionais para a função. O presente trabalho visa analisar a formação de mediadores em dois museus de ciência, a partir da compreensão dos saberes mobilizados nesse processo. A coleta de dados consistiu na observação de cursos de formação de mediadores, em entrevistas com profissionais atuantes nos processos estudados e questionários autoaplicados com mediadores. A formação de mediadores incluiu cursos organizados pelos museus em questão, mas também a formação acadêmica prévia, a prática e o diálogo entre os mediadores. Os processos estudados envolveram, com ênfases distintas em cada caso, saberes disciplinares, da formação profissional e da experiência, todos essenciais a uma boa prática.

Palavras-chave: Museu de ciência. Educação não formal em ciências. Mediação. Formação de mediadores.

\section{FORMACIÓN DE MEDIADORES EN MUSEOS DE CIENCIAS: CONOCIMIENTOS Y PRÁCTICAS}

RESUMEN: Aunque haya uso frecuente de mediación humana en museos de ciencias, hay poco investimento en la formación de profesionales para la función. El presente trabajo busca analizar la formación de mediadores en dos museos de ciencias, a partir de la comprensión de los saberes movilizados en ese proceso. La recopilación de datos consistió en la observación de cursos de formación de mediadores, entrevistas con profesionales actuantes en los procesos estudiados y cuestionarios auto-aplicados con mediadores. La formación de mediadores incluyó cursos organizados por los museos en cuestión y también suformación académica anterior, la práctica y el dialogo entre los mediadores. Los procesos estudiados incluyen, con énfasis distintas en cada caso,saberes disciplinarios de formación profesional y de la experiencia todos esenciales a una buena práctica.

Palabras clave: Museo de ciencias. Educación no formal en ciencias. Mediación. Formación de mediadores.

\footnotetext{
* Universidade Federal do Estado do Rio de Janeiro (UNIRIO) Rio de Janeiro, RJ - Brasil Mestre em Ciências Sociais Aplicadas: Museologia e Patrimônio pela Universidade Federal do Estado do Rio de Janeiro (UNIRIO) Museu de Astronomia e Ciências Afins (MAST/MCTI). Bolsista de pesquisa do Programa de Capacitação Institucional (PCI) MCTI) na Coordenação de Educação em Ciências do MAST no Grupo de Pesquisa em Educação em Ciências em Espaços Não Formais (GECENF). E-mail: isabelgomes@mast.br

${ }^{*}$ Museu de Astronomia e Ciências Afins (MAST/MCTI) Rio de Janeiro, RJ - Brasil Doutora em Ciências Humanas: Educação pela Pontifícia Universidade Católica do Rio de Janeiro (PUC-Rio). Pesquisadora da Coordenação de Educação em Ciências do Museu de Astronomia e Ciências Afins (MAST/MCTI) no Grupo de Pesquisa em Educação em Ciências em Espaços Não Formais (GECENF). E-mail: sibele@mast.br.
}

DOI - http://dx.doi.org/10.1590/1983-21172016180102 


\section{SCIENCE MUSEUM MEDIATORS' EDUCATION: KNOWLEDGE AND PRACTICES}

ABSTRACT: Despite the frequent use of human mediation in science museums, there is little investment in training professionals for the role. The present work analyzes mediatortraining in two science museums by understanding the knowledge comprehension mobilized in these processes. Data collection consisted of training courses for mediators' observation, interviews with professionals working in the studied processes and self-administered questionnaires with mediators. The mediator training included courses organized by the museums in question, but also prior academic training, practice and dialogue among mediators. The processes studied involved disciplinary, training and experience knowledge, with different emphasis in each case.

Keywords: Science museums. Informal science education. Mediation. Mediator training. 


\section{INTRODUÇÃO}

A instituição museológica ao longo de sua trajetória histórica assumiu diferentes funções. Considerando o conceito moderno de museu, a educação é um fator relevante, que tem importância, sobretudo, a partir da segunda metade do século XX.

Valente (2009) define educação como um processo de transmissão, aprendizado e produção de conhecimentos no campo das ideias, conceitos, valores e hábitos próprios da cultura de determinado grupo social. Nessa perspectiva, considera que o museu, enquanto local onde a cultura é recontextualizada e os saberes são reelaborados e socializados, é intrinsecamente relacionado à educação: “[...] independentemente de contar ou não com um programa específico de atividades pedagógicas, a instituição é em si mesma um meio educativo" (VALENTE, 2009, p. 88).

A educação em museus se diversificou no século XIX no contexto de sua abertura a um público mais amplo e no redirecionamento de suas finalidades, incluindo a relação com instituições de educação formal:

\footnotetext{
Necessidades educacionais no final do século XIX - expansão do sistema de escolarização formal e modernização dos métodos e técnicas de ensino - resultaram na formatação de novas teorias pedagógicas que incentivam a relação das escolas com os museus. Essas relações, que começaram de forma incipiente e pouco organizada, foram paulatinamente se estruturando em ações específicas. (MARTINS, 2011, p. 74)
}

Sobretudo a partir da segunda metade do século XX, a função educativa do museu torna-se prioritária, acompanhando um movimento de democratização do acesso a essa instituição. Nesse período, fóruns importantes no âmbito da comunidade museológica, como o Seminário Internacional da Unesco: O papel dos museus na educação de 1952; a Mesa Redonda do Chile (1972), a Declaração de Quebec (1984) e a Declaração de Caracas (1992) discutem essa questão e colocam em pauta o papel social e educacional dessa instituição (BRUNO, 1995).

Os museus de ciência, em particular, mantêm em sua história forte ligação com as questões de cunho educacional (VALENTE, 1995). Atualmente, são protagonistas no desenvolvimento de pesquisas na área de educação em museus, buscando a construção e o aprofundamento de fundamentação teórica própria, que sirva de alicerce para suas práticas educativas.

As exposições com temática científica podem ser encontradas em uma variedade de tipos de instituições, desde os tradicionais museus de história natural aos contemporâneos centros de ciência. Os museus de ciência em um primeiro momento de sua história atendiam prioritariamente a finalidades de pesquisa baseada em suas coleções. A partir da Revolução Industrial, se relacionam ao desenvolvimento de uma cultura técnica e industrial, funcionando como instrumento de incentivo à inovação e de exaltação da ciência como promotora do progresso. No século XX situam-se de forma mais crítica, como locais de compreensão das relações entre ciência, tecnologia e sociedade (JACOMY, 2007).

Em museus de ciência nos dias de hoje, a ciência "[...] é compreendida 
como processo e vista como parte integrante da cultura geral" (VALENTE, 2008, p. 64). A ciência, apresentada em sua historicidade, é considerada em contexto ao cotidiano do visitante. Nesse sentido, os museus de ciência tendem a:

[...] fazer a síntese dos conhecimentos e discuti-los com o público. O visitante não é considerado apenas um receptor desse conhecimento, mas também um criador de novos saberes e de novos conhecimentos, um ator no processo de ampliação da cultura científica [...]. Esse posicionamento transforma os museus de ciência em locais de encontro, de discursos, de discussão e troca de informações, abertos a todos e conectados às redes internacionais de informação e de popularização do conhecimento. (NASCIMENTO; VENTURA, 2005, p. 446)

É inerente ao museu a representação da realidade, a partir da coleta e exposição de seus fragmentos. Durante a formação de coleções até a organização de exposições e a comunicação com o público, ocorrem, em diversos níveis, processos de recontextualização e reinterpretação. $\mathrm{O}$ museu se constitui como um meio que propicia uma aproximação entre a sociedade e seu patrimônio cultural. Nessa perspectiva, os processos de mediação são considerados fundamentais às finalidades dos museus.

De acordo com Davallon (2007), o termo mediação pode ser definido pela presença de um terceiro elemento, que serve de intermediário entre outros dois elementos, cuja ação provoca um efeito sobre os destinatários. Ou seja, a mediação implica transformação, não apenas em transmissão de uma mensagem. A comunicação se dá pela operação desse terceiro elemento. A mediação em museus envolve potencialmente vários níveis de diálogo: entre o público e as exposições; entre os sujeitos e o saber; entre a arte, a ciência, a história e a sociedade.

Entre os temas referentes a processos de mediação em museus, o da mediação humana presencial é especialmente pertinente para museus de ciência (BRITO, 2008; MARANDINO, 2008a; MORAES et al., 2007; RODARI; MERZAGORA, 2007). Levando-se em consideração a atuação dessas instituições como espaços de educação não formal e de divulgação da ciência, a relação com o público por meio de mediadores torna-se uma prioridade.

Guia, monitor, anfitrião, animador, explicador são algumas das denominações que esse profissional de museus recebe em diversos países, além de mediador. Considera-se que a existência dessas várias denominações é relacionada a diferentes concepções sobre o papel que um mediador de museus deve exercer. Todos esses termos expressam alguma característica ou função que o mediador pode desempenhar, mas que não são as únicas nem as mais importantes. Afinal, a natureza primordial dessa atividade é ser múltipla.

$\mathrm{Na}$ prática, os mediadores comumente podem se dedicar a variadas tarefas no museu, relacionadas ao atendimento ao público: dialogam com os visitantes e orientam o uso de aparatos interativos nas exposições; são anfitriões, recebendo e organizando grupos agendados; realizam atividades educativas específicas como showsde ciência; participam de atividades artísticas, como as teatrais, entre outras atribuições. O mediador mobiliza necessariamente habilidades diversas para executar seu papel. Nesse sentido, esse profissional pode ser considerado: 
[...] um terceiro elemento, num processo de construção de uma qualquer realidade fortemente comunicacional na qual desempenha o papel simultaneamente de tradutor, facilitador, negociador, anfitrião, [...] moderador [...], orientador, catalisador e intermediário entre dois ou mais interlocutores, tendo como cenário diferentes contextos de sociabilidade, sendo por isso sua identidade redefinida constantemente. (AZEVEDO, 2003, p. 56)

No Brasil, a presença de mediadores é muito frequente em museus de ciência, onde esses profissionais têm importância estratégica (MARANDINO, 2008a). A despeito da grande importância atribuída aos mediadores em museus de ciência e da complexidade inerente à sua função, há pouco investimento na sua capacitação e sua identidade profissional não é claramente definida (RODARI; MERZAGORA, 2007).

O cuidado com a formação de mediadores tornou-se tema obrigatório nos museus de
ciências e faz parte de um processo de formação continuada em muitos deles; é tema de
pesquisas em várias instituições museais brasileiras; vem sendo proposta como disciplina
curricular em cursos de formação de professores de ciências/biologia, em universidades
federais [...], enquanto muitos museus encontram ainda dificuldades para formar regular-
mente seus mediadores. (RIBEIRO; FRUCCHI, 2007, p. 70)

O perfil das equipes de mediadores, em geral, é de jovens, estudantes do Ensino Médio e de graduação em diversas áreas do conhecimento, mas, sobretudo, em biologia, química, física, geografia e áreas afins (CAFFAGNI, 2010). Frequentemente são estagiários ou colaboradores sem vínculo empregatício de longo prazo e, por isso, há uma grande rotatividade nas equipes, o que demanda a realização periódica de atividades de formação. Considera-se essencial à atividade de mediação em museus de ciência o aperfeiçoamento teórico e prático da formação dos profissionais envolvidos nessa atividade.

Diante desse panorama, o presente trabalho visa analisar os processos de formação de mediadores em museus de ciência, a partir da compreensão dos saberes mobilizados nesse processo, levando-se em conta a perspectiva das instituições em questão e também dos mediadores que aí atuam.

\section{OS SABERES DOCENTES COMO REFERENCIAL DE ANÁLISE}

As pesquisas em educação em museus, por constituírem uma área recente, ainda carecem de referenciais teóricos próprios e da construção destes representa um de seus principais desafios. Muitos pesquisadores dessa área vêm utilizando referenciais provenientes do campo da educação, originalmente aplicados a espaços de educação formal (MARANDINO, 2006). Nessa investigação pretende-se seguir o mesmo caminho, abordando a questão da formação de mediadores tendo como referência os saberes docentes, na concepção de Maurice Tardif (2010).

Historicamente os estudos sobre os saberes docentes têm relação com um movimento de profissionalização do magistério, sobretudo nos Estados Unidos da América na década de 1980, que incluiu o interesse pelo estabelecimento de 
um repertório de conhecimentos profissionais para o ensino e o entendimento da natureza desses conhecimentos. A questão tem grande relevância para as pesquisas em ciências da educação nos Estados Unidos desde essa época, na Europa, a partir da década de 1990 e, mais recentemente, na América Latina, especialmente no Brasil (BORGES; TARDIF, 2001; TARDIF, 2010). Nesse contexto,

[...] as produções a respeito da temática de saberes docentes têm ocupado papel de destaque na formação de professores, o que é atribuído, em grande parte, ao seu potencial no desenvolvimento de ações formativas que vão além de uma abordagem acadêmica, envolvendo as dimensões pessoal, profissional e organizacional da profissão docente. (ALMEIDA; BIAJONE, 2007, p. 283)

Tardif (2010) procura identificar e compreender a natureza dos saberes que servem de base à prática dos professores, construindo um modelo a partir de categorias dos próprios docentes. O autor identifica e caracteriza os saberes docentes e descreve suas formas de aquisição, contribuindo para a discussão sobre a formação para o magistério.

$\mathrm{O}$ autor considera que o saber docente é um saber social - mesmo que relacionado à identidade de cada professor - temporal e a serviço do trabalho.O saber docente é ainda um saber plural, pois tem diversas naturezas e origens. Provém, além das experiências individuais, da formação para o magistério na universidade, dos programas escolares e da experiência em sala de aula. Portanto, o saber docente é composto de: saberes da formação profissional, saberes disciplinares, saberes curriculares e saberes da experiência.

Os saberes da formação profissional, ancorados nas ciências humanas e da educação, são transmitidos pelas instituições de formação de professores com o intuito de serem incorporados à prática do professor. São:

[...] saberes destinados à formação científica ou erudita dos professores [...], apresentam-se como doutrinas ou concepções provenientes de reflexões sobre a prática educativa no sentido amplo do termo, reflexões racionais e normativas que conduzem a sistemas mais ou menos coerentes de representação e de orientação da atividade educativa [...]. (TARDIF, 2010, p. 37)

Por sua vez, os saberes disciplinares correspondem a diversos campos do conhecimento, como, por exemplo, matemática, física, história, e encontram-se sob forma de disciplinas nos diversos cursos universitários. Nas palavras do autor:

[...] a prática docente incorpora [...] saberes sociais definidos e selecionados pela instituição universitária. [...] correspondem aos diversos campos do conhecimento, aos saberes que dispõe nossa sociedade, tais quais se encontram hoje integrados nas universidades, sob forma de disciplinas [...] são transmitidos nos cursos e departamentos universitários independentes das faculdades de educação e dos cursos de formação de professores [...]. (TARDIF, 2010, p. 38)

Já os saberes curriculares remetem aos discursos, objetivos, conteúdos e 
métodos definidos pela instituição escolar. Apresentam-se sob a forma de programas escolares que balizam a prática docente. Ou seja, esses saberes:

[...] correspondem aos discursos, objetivos, conteúdos e métodos a partir dos quais a instituição escolar categoriza e apresenta os saberes sociais por ela definidos e selecionados como modelos da cultura erudita e de formação para a cultura erudita. Apresentam-se concretamente sob a forma de programas escolares que os professores devem aprender a aplicar. (TARDIF, 2010, p. 38)

Os professores desenvolvem ao longo do tempo saberes particulares que não têm origem na universidade ou no currículo e não são sistematizados, mas provêm e são constituintes da prática, aos quais Tardif (2010, p. 38) denomina saberes da experiência.

[...] os próprios professores, no exercício de suas funções e na prática de sua profissão, desenvolvem saberes específicos, baseados em seu trabalho cotidiano e no conhecimento de seu meio [...], brotam da experiência e são por ela validados. Eles incorporam-se à experiência individual e coletiva sob a forma de habitus e habilidades, de saber-fazer e saber-ser.

A partir da compreensão dos saberes docentes, pode-se afirmar que:

[...] o professor ideal é alguém que deve conhecer sua matéria, sua disciplina e seu programa, além de possuir certos conhecimentos relativos às ciências da educação e à pedagogia e desenvolver um saber prático baseado em sua experiência cotidiana com os alunos. (TARDIF, 2010, p. 39)

Buscando aproximações entre essa definição do que seria um professor ideal com um mediador de museus, podem ser enumerados atributos interessantes à prática de mediação, e pode-se entendê-los a partir das categorias estabelecidas por Tardif (2010).

É útil a um mediador ter domínio acerca dos conteúdos temáticos presentes nas exposições em que trabalha. Conhecer tais conteúdos é condição essencial para que esse profissional não seja um transmissor de informações previamente selecionadas por outros, mas um verdadeiro mediador que, dotado desse conhecimento, conduz o diálogo com o público. O mediador idealmente precisa dominar um saber disciplinar.

Por outro lado, se a intenção não for apresentar uma visão de especialista, mas provocar o interesse sobre as temáticas propostas através de contextualizações, é imprescindível deter as ferramentas que propiciem uma boa comunicação com diferentes tipos de público. Compreende-se que o mediador enriqueceria sua prática ao mobilizar conhecimentos provenientes das ciências da educação e temas correlatos, ou seja, saberes da formação profissional.

Tardif (2010) considera que o professor em sua prática é influenciado por normas, discursos, objetivos que orientam a instituição escolar na seleção dos saberes sociais a serem apresentados por ela. A prática do mediador no 
museu, assim como a do professor, é conduzida em uma instituição com uma história, com normas, propostas museológica, museográfica e educativa, que a influenciam e podem ser compreendidas como um saber curricular.

$\mathrm{O}$ autor propõe que os saberes da experiência estão a serviço de um contexto de múltiplas interações aos quais os professores estão submetidos.

\begin{abstract}
No exercício cotidiano de sua profissão, os condicionantes aparecem relacionados a situações concretas que não são passíveis de definições acabadas, que exigem improvisação e habilidade pessoal, bem como a capacidade de enfrentar situações mais ou menos transitórias e variáveis. Ora, lidar com condicionantes e situações é formador: somente isso permite ao docente desenvolver o habitus[...] que lhe permitirão justamente enfrentar os condicionantes imponderáveis de sua profissão (TARDIF, 2010, p. 49).
\end{abstract}

De acordo com Marandino (2008b), o mediador em sua prática também convive com situações inusitadas, as quais devem superar por meio da improvisação e da criatividade, devido à heterogeneidade dos públicos e à complexidade dos processos de mediação em museus. Nesse mesmo sentido, Queiroz (2003) considera que a atividade de mediação envolve um talento artístico que é necessário para superação de tais circunstâncias imprevistas, inerentes à relação do mediador com o público, por meio da reflexão na ação.

O uso do trabalho de Tardif (2010) como ferramenta teórica e analítica no presente trabalho foi feito mediante adaptações. $\mathrm{O}$ autor investiga os saberes nos quais os professores baseiam a sua prática no contexto específico da escola. Esta pesquisa trata dos saberes de mediadores em um espaço tipicamente de educação não formal.

De acordo com Tardif (2010), os saberes provêm de diferentes fontes como: a instituição universitária, a própria prática, e escola e demais instâncias reguladoras da profissão docente. Na presente pesquisa, o foco foram os saberes transmitidos por museus de ciência, embora entenda-se que os saberes dos mediadores também tenham origem mais diversificada. Frequentemente esses profissionais são graduados em diversas áreas do conhecimento, onde podem ter contato com saberes disciplinares, da formação profissional e também da experiência. Porém, a construção dos saberes dos mediadores de maneira mais abrangente não foi objeto da presente pesquisa.

É importante ressaltar que o trabalho de mediação se relaciona a saberes próprios, distintos daqueles dos professores, como descrito a seguir:

I) saberes compartilhados com a escola - saber disciplinar, saber da transposição didática, saber do diálogo e saber da linguagem; II) saberes compartilhados com a escola no que dizem respeito à educação em ciência - saber da história da ciência, saber da visão de ciência, saber das concepções alternativas; III) saberes mais propriamente de museus - saber da história de instituição, saber da interação com professores, saber da conexão, saber da história da humanidade, saber da expressão corporal, saber da manipulação, saber da ambientação e saber da concepção da exposição. (QUEIROZ et al., 2002, p. 81) 


\section{METODOLOGIA}

O tema abordado na presente pesquisa - a formação de mediadores em museus - é influenciado por intenções, significados e finalidades, expressos pelos diferentes tipos de sujeitos envolvidos nos processos estudados, cuja compreensão considera-se ser mais proficuamente apreendida por meio de uma abordagem qualitativa.

De acordo com Bogdan e Biklen (1982), em metodologias qualitativas de pesquisa: os dados coletados são prioritariamente descritivos e a compreensão dos processos é mais importante do que a dos produtos. Esse tipo de pesquisa é caracteristicamente multimetodológico, isto é, usa-se uma grande variedade de procedimentos e instrumentos de coleta de dados (ALVES-MAZZOTTI; GEWANDSZNAJDER, 1999).

Foram coletados dados no Museu Espaço Ciência Viva (ECV) e no Museu de Astronomia e Ciências Afins (MAST/MCTI), ambos localizados na cidade do Rio de Janeiro. O ECV, organizado juridicamente como uma sociedade civil sem fins lucrativos, foi fundado em 1983 por um grupo de cientistas, pesquisadores e educadores. O objetivo da instituição é a "[...] divulgação e a desmistificação da ciência, tornando-a acessível [...], bem como a melhoria da qualidade do ensino de ciências e da matemática" (COUTINHO-SILVA et al., 2005, p. 24).

O museu oferece ao seu público escolar e não escolar exposição permanente composta de cerca de 60 módulos que tratam de diversas temáticas relacionadas a áreas como: física, matemática, biologia, astronomia, dentre outros.

O MAST, fundado em 1985, tem como missão atualmente: “ampliar o acesso da sociedade ao conhecimento científico e tecnológico por meio da pesquisa, preservação de acervos, divulgação e história da ciência e da tecnologia no Brasil" (MUSEU DE ASTRONOMIA E CIÊNCIAS AFINS, 2010, p. 11).

Oacervo museológico do MAST é composto por mais de dois mil objetos, destacando-se a coleção de instrumentos científicos oriundos do Observatório Nacional. Nos campos da divulgação da ciência e educação em museus, o museu realiza ações tais quais: o programa observação do céu, atividades itinerantes de divulgação da ciência, visitação mediada, cursos de formação continuada de professores, entre outras ${ }^{1}$.

A primeira etapa da coleta de dados consistiu na observação dos cursos: "Curso de capacitação de mediadores para atuação em ambientes de ensino não formal" e "Mediação em museus e centros de ciência: teoria e prática", realizados no início do ano de 2012, no ECV e no MAST, respectivamente. O objetivo das observações foi a descrição de ações de formação inicial dos mediadores destas instituições ${ }^{2}$.

A observação consiste em uma experiência direta, que possibilita o contato estreito do pesquisador com o objeto de estudo. Permite, assim, que o observador se aproxime mais da perspectiva dos sujeitos (LUDKE; ANDRE, 1986) e obtenha informações sobre a realidade destes em seus próprios contextos, tendo acesso a informações que não são obtidas por meio de perguntas (MINAYO, 1994). 
A cada atividade realizada durante os cursos foram preenchidos roteiros de observação que orientaram a coleta de informações descritivas sobre os mesmos. Constavam também no roteiro de observação tópicos a serem identificados durante as discussões que se referiam aos diferentes saberes abordados nos cursos. São eles: conceitos específicos dos saberes de referência; história do museu; objetivos educativos do museu; tipos de público a serem atendidos; conceitos da área de educação e/ou educação em museus; aspectos pedagógicos relativos ao atendimento ao público; prática de mediação (exemplos de experiências anteriores).

Durante as observações, as falas dos responsáveis pelas atividades nos dois cursos foram registradas, por meio de gravação em áudio, as quais foram posteriormente transcritas em sua totalidade.

Em uma segunda etapa da coleta de dados, foram feitas entrevistas semiestruturadas com o chefe da Coordenação de Educação do MAST e um dos vice-presidentes do ECV, os quais participam da concepção e execução dos cursos de formação de mediadores observados, assim como das ações de formação em serviço propostas pelos museus. Esses processos puderam então ser descritos de maneira mais abrangente. A entrevista é um instrumento adequado para tratar-se de temas complexos, ao explorá-los em profundidade, e permite que o interlocutor expresse sua interpretação a respeito de determinada questão a partir de suas experiências (QUIVY; CAMPENHOUDT, 2008; ALVES-MAZZOTTI; GEWANDSZNAJDER, 1999).

A última etapa da coleta de dados consistiu na utilização de questionário autoadministrado disponibilizado aos mediadores do ECV e do MAST em mãos ou por correio eletrônico, que foram preenchidos individualmente, durante o tempo julgado necessário.Foram considerados para a pesquisa os mediadores que trabalhavam na mediação com o público dos museus em questão há mais de um mês e que tinham vínculos formais ${ }^{3}$ com as instituições.

A partir dos questionários foi traçado um perfil dos mediadores e foram acessadas concepções dos sujeitos a respeito de sua formação, no que se refere mais especificamente à importância: dos cursos para mediadores e ações de formação em serviço; da prática e dos mediadores mais experientes e da formação acadêmica prévia. Os questionários continham questões objetivas ( $\operatorname{sim} /$ não) e discursivas que foram quantificadas e organizadas em categorias de análise referentes a cada questão proposta.

\section{RESULTADOS E DISCUSSÃO}

\section{Perfil dos mediadores}

A equipe de mediadores do ECV era formada por um total de 32 jovens entre 17 e 26 anos, com média de 21 anos de idade. A maioria dos mediadores era do sexo feminino (23) e apenas nove do sexo masculino. Já no MAST, a média de idade era de 27 anos, variando entre 16 e 47 anos. De um total de 17 mediadores, 10 eram do sexo masculino e sete do sexo feminino. 
A maioria dos mediadores no ECV era estudante de Ensino médio 4 (15) e grande parte era graduando (13). Havia também um mediador com apenas o Ensino Médio completo, dois graduados e um mestre. A maioria cursava ou havia completado o curso de Biologia (8), seguido de Enfermagem (3), Psicologia (1), Biomedicina (1), Cenografia (1), Química (1) e Física (1). No MAST, a maior parte dos mediadores era estudante de graduação (11) e dois eram estudantes do Ensino Médio. Um tinha até o Ensino Superior completo, dois haviam concluído o mestrado e um, o doutorado. Entre os cursos superiores, a maior parte era em Física (7), seguido de Química (3), Astronomia (2), Pedagogia (1), Ciências Ambientais (1) e Geografia (1).

Todos os mediadores do ECV tiveram a sua primeira experiência de trabalho com mediação neste museu, e o tempo médio de vínculo à instituição foi de 10 meses. O tempo médio de experiência no MAST foi de dois anos e 10 meses, e três dos mediadores relataram experiências anteriores de trabalho com mediação.

\section{Os saberes na formação de mediadores em museus}

As ações de formação de mediadores desempenhadas por ambas as instituições estudadas tiveram semelhanças. Consistiram em um curso de curta duração realizado no início do ano e diversas ações de formação em serviço, como é comum em diversos museus de ciência (MASSARANI; MERZAGORA; RODARI, 2007).

Os cursos de formação inicial tiveram como foco fornecer aos mediadores novatos ferramentas básicas que lhes permitissem executar seu trabalho, por meio da apresentação de algumas das atividades que os museus disponibilizam ao seu público, embasada por conteúdos teóricos das ciências de referência associados a essas atividades, da educação em museus e por experiências anteriores. O curso de mediadores organizado pelo ECV teve duração de cerca de 18 horas e consistiu em 11 atividades (Quadro 1).

A formação de mediadores se deu de maneira contínua após os cursos, por meio das seguintes ações de formação em serviço: observação da atuação de mediadores experientes; capacitações pontuais para atividades específicas; reuniões periódicas; estudo orientado; participação em cursos externos, palestras e seminários.

Ao ser feita uma análise do teor dos conteúdos abordados no curso do ECV, entende-se que houve uma ênfase nos saberes disciplinares, frequentemente relacionadas a Química, Física e Biologia, que também são tema de diversas atividades educativas do museu. Foi observado que o discurso dos responsáveis pela condução das atividades do curso, que incluiu pesquisadores nas áreas supracitadas, muitas vezes refletiu este caráter disciplinar:

Pode ser um lipossoma, pode ser uma vesícula endocítica. Quando ela acaba de comer, engole assim uma parte do meio extracelular, internaliza um pedaço da membrana e forma uma vesícula [...]. Pode ser uma vesícula que ela produziu de um outro compartimento celular, [...] do Golgi. ${ }^{5}$ 
Quadro 1 - Atividades do "Curso de capacitação de mediadores para atuação em ambientes de ensino não formal"

\begin{tabular}{|c|c|c|}
\hline ATIVIDADE & PRINCIPAIS TEMÁTICAS & METODOLOGIAS \\
\hline Abertura do curso & O Espaço Ciência Viva & $\begin{array}{l}\text { Apresentação oral } \\
\text { com powerpoint }\end{array}$ \\
\hline Arte com sucata & Reciclagem de materiais & Atividade prática \\
\hline $\begin{array}{l}\text { Divulgando saberes } \\
\text { de } 6 \text { a } 12 \text { anos }\end{array}$ & Educação Infantil & $\begin{array}{c}\text { Apresentação oral com } \\
\text { powerpoint e dinâmica de } \\
\text { grupo }\end{array}$ \\
\hline Trabalhando com o sangue & $\begin{array}{c}\text { Biologia } \\
\text { (Sistema Circulatório } \\
\text { Humano) }\end{array}$ & $\begin{array}{l}\text { Apresentação oral e } \\
\text { Atividade prática }\end{array}$ \\
\hline Brincando com a Biologia & $\begin{array}{l}\text { Biologia } \\
\text { (Genética) }\end{array}$ & Atividade prática \\
\hline Trabalhando com o sangue & $\begin{array}{c}\text { Biologia } \\
\text { (Sistema Circulatório } \\
\text { Humano) }\end{array}$ & Atividade prática \\
\hline Ciência e Arte & $\begin{array}{c}\text { Biologia } \\
\text { (Citologia) } \\
\text { e Arte-Educação }\end{array}$ & Atividade prática \\
\hline Faça você mesmo & $\begin{array}{c}\text { Biologia } \\
\text { (Microscopia) }\end{array}$ & Atividade prática \\
\hline Física nas cores & $\begin{array}{l}\text { Física } \\
\text { (Óptica) }\end{array}$ & $\begin{array}{l}\text { Apresentação oral e } \\
\text { Atividade prática }\end{array}$ \\
\hline $\begin{array}{c}\text { Conhecendo } \\
\text { Micro-organismos }\end{array}$ & $\begin{array}{c}\text { Biologia } \\
\text { (Microbiologia) }\end{array}$ & $\begin{array}{l}\text { Apresentação de vídeo } \\
\text { e atividade prática }\end{array}$ \\
\hline Sexualidade & $\begin{array}{c}\text { Biologia } \\
\text { (Sistema Reprodutivo) }\end{array}$ & Discussão em grupo \\
\hline
\end{tabular}

Fonte: UNIRIO/MAST - Pesquisa "Formação de Mediadores em Museus de Ciência", 2013.

Os saberes disciplinares também estão presentes nas ações de formação em serviço disponibilizadas aos mediadores do ECV, como: oficinas realizadas ao longo do ano, estudo individual e coletivo e reuniões com pesquisadores. Por meio destas, deseja-se que haja uma complementação teórica dos conteúdos das ciências de referência interessantes à prática de mediação nessa instituição. 
O destaque dos saberes disciplinares durante a formação de mediadores no ECV condiz com seu perfil - em grande parte estudantes de Ensino Médio - e também com concepção de mediação adotada na instituição. Como nota-se na fala abaixo, o mediador é aí compreendido como um promotor de diálogo, pautado nos interesses do público, que, portanto, necessita de um conhecimento abrangente dos temas tratados:

Um bom mediador é um sujeito primeiro comunicativo. E ele tem que ser uma pessoa paciente, porque ele tem que esperar o tempo do visitante. E ele tem que falar na medida certa. Tem que ser um sujeito interessado em estudar, porque você não tem como fazer mediação daquilo que você não conhece. [...]Não um sujeito capaz de reproduzir informação. Mas um sujeito capaz de ajudar alguém a construir um conceito novo. (Vice-presidente do ECV, 28/08/2012)

Compreende-se que o domínio dos saberes disciplinares é imprescindível, na medida em que permite aos mediadores lidar com as diferentes interpretações dos visitantes, de maneira a relacionar os assuntos abordados a questões que os motivem, aproximando a ciência à sua realidade.

No caso do MAST, os saberes disciplinares, ainda que presentes, tiveram menor destaque. O curso de formação de mediadores "Mediação em museus e centros de ciência: teoria e prática" foi pautado mais fortemente em saberes da formação profissional (Quadro 2). Isso fica claro em seu objetivo: "capacitar mediadores de museus e centros de ciência, a partir da discussão de teorias educacionais e saberes envolvidos nas práticas de mediação" . No curso de mediadores do MAST, fez-se uso de conhecimentos produzidos, sobretudo no campo da educação em museus, para fundamentar a atuação futura de seus mediadores.

Considera-se que essa abordagem enfatizou saberes da formação profissional, que, para Tardif (2010, p. 37), são "saberes transmitidos pelas instituições de formação de professores [que] [...] não se limitam a produzir conhecimentos, mas procuram também incorporá-las à prática do professor". Nota-se na fala abaixo esse viés da ligação entre teoria e prática:

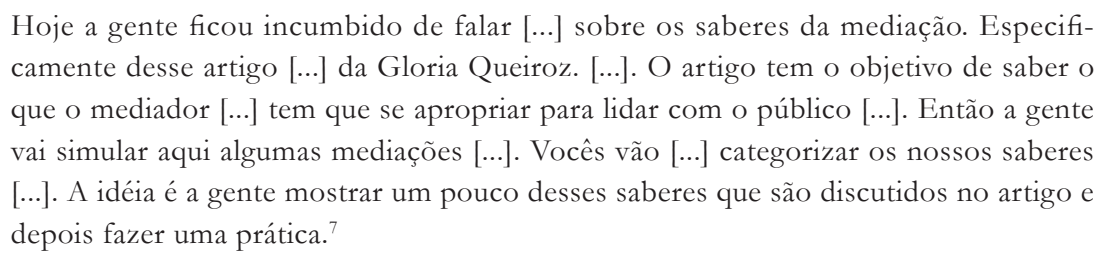

$\mathrm{Na}$ formação em serviço, essa ênfase nos saberes da formação profissional permanece. Por meio de estudo, participação em palestras e reuniões de avaliação, pretende-se que o mediador ao longo do tempo se aproprie de conceitos e teorias na área de educação que alicerçam seu trabalho. 
Quadro 2 - Atividades do curso "Mediação em museus e centros de ciência: teoria e prática"

\begin{tabular}{|c|c|c|}
\hline ATIVIDADES & PRINCIPAIS TEMÁTICAS & METODOLOGIAS \\
\hline Audiências em museus & $\begin{array}{l}\text { Estudos de público e } \\
\text { avaliação em museus }\end{array}$ & $\begin{array}{c}\text { Apresentação oral com } \\
\text { powerpoint }\end{array}$ \\
\hline $\begin{array}{l}\text { Educação em museus e } \\
\text { espaços não formais }\end{array}$ & $\begin{array}{c}\text { Educação em museus } \\
\text { de ciências: abordagem } \\
\text { histórica }\end{array}$ & $\begin{array}{c}\text { Apresentação oral com } \\
\text { powerpoint }\end{array}$ \\
\hline Trilhas educativas do MAST & $\begin{array}{l}\text { Relação museu-escola: } \\
\text { experiência do MAST }\end{array}$ & $\begin{array}{c}\text { Apresentação oral com } \\
\text { powerpoint }\end{array}$ \\
\hline $\begin{array}{l}\text { Tecendo redes por um } \\
\text { planeta saudável }\end{array}$ & $\begin{array}{c}\text { Relação museu-escola: } \\
\text { experiência do Museu da } \\
\text { Vida }\end{array}$ & $\begin{array}{c}\text { Apresentação oral com } \\
\text { powerpoint }\end{array}$ \\
\hline Mediação em museus & $\begin{array}{l}\text { Mediação em museus: } \\
\text { conceitos e características }\end{array}$ & $\begin{array}{c}\text { Apresentação oral com } \\
\text { powerpoint }\end{array}$ \\
\hline Saberes da mediação & $\begin{array}{l}\text { Mediação em museus: } \\
\text { conceitos e características }\end{array}$ & Discussão em grupo \\
\hline $\begin{array}{l}\text { Motivação na atividade } \\
\text { “Brincando de Matemático” }\end{array}$ & $\begin{array}{l}\text { Aprendizagem, motivação e } \\
\text { mediação em museus }\end{array}$ & $\begin{array}{c}\text { Apresentação oral com } \\
\text { powerpoint }\end{array}$ \\
\hline $\begin{array}{l}\text { Mediação segundo os } \\
\text { mediadores }\end{array}$ & $\begin{array}{c}\text { Experiências de mediação } \\
\text { em museus }\end{array}$ & Discussão em grupo \\
\hline $\begin{array}{c}\text { Aparatos interativos em } \\
\text { exposições }\end{array}$ & $\begin{array}{l}\text { Interatividade em museus } \\
\text { de ciências }\end{array}$ & $\begin{array}{c}\text { Apresentação oral com } \\
\text { powerpoint }\end{array}$ \\
\hline $\begin{array}{l}\text { Exposição: “olhar o céu, } \\
\text { medir a Terra" }\end{array}$ & $\begin{array}{l}\text { Concepção e montagem } \\
\text { de exposições }\end{array}$ & $\begin{array}{c}\text { Apresentação oral com } \\
\text { powerpoint }\end{array}$ \\
\hline Oficina de mediação & $\begin{array}{c}\text { Experiências de mediação } \\
\text { em museus }\end{array}$ & $\begin{array}{l}\text { Visita a exposições e } \\
\text { discussão em grupo }\end{array}$ \\
\hline $\begin{array}{c}\text { Programa de Observação do } \\
\text { Céu }\end{array}$ & Astronomia & Apresentação oral \\
\hline Planetário Inflável & Astronomia & Atividade prática \\
\hline $\begin{array}{c}\text { Programa de Observação do } \\
\text { Céu }\end{array}$ & Astronomia & Atividade prática \\
\hline
\end{tabular}


Foi frisada no MAST a relação da pesquisa acadêmica com a prática educativa, que se refletiu na formação de seus mediadores. Essa abordagem está presente nas próprias finalidades da Coordenação em Educação em Ciências do MAST, onde estudos acadêmicos em educação em museus e temas correlatos são realizados desde 1996 com objetivo de avaliar suas atividades educacionais (CAZELLI; COIMBRA, 2010). É interessante notar que grande parte dos mediadores nessa instituição tem acesso a uma formação para a pesquisa acadêmica, pois desenvolvem projetos de pesquisa na área, por meio de bolsas vinculadas ao $\mathrm{CNPq}^{8}$.

Apesar da ênfase nos saberes disciplinares no caso do ECV e dos saberes da formação profissional no caso do MAST, foi observada em ambos uma preocupação com a aplicabilidade prática das teorias e dos conceitos abordados. Houve uma valorização das experiências prévias, que por diversas vezes embasaram as discussões:

\footnotetext{
Nós vamos falar hoje da proposta metodológica que chama "Trilhas educativas entre o MAST e a escola", que é uma atividade [...] da visita escolar ao Museu de Astronomia. [...] A gente vai apresentar primeiro alguns estudos da área, que tenham a ver com mediação, visitas orientadas, visitas escolares. [...] Eu vou apresentar alguns estudos e depois [...] falar do caso do MAST. ${ }^{9}$
}

Foi esclarecida também de diversas formas a concepção de mediação adotada nas instituições, como, por exemplo, durante apresentação oral no curso do ECV:

É o mediador [...] que tem a maior importância [...]. O mediador é aquele indivíduo cuja função é provocar a curiosidade do visitante. Não é de dar respostas, não é demonstrar que tem informação. O papel do mediador nesse museu é o de desafiar o indivíduo. Desafiar provocando a curiosidade. Tentar despertar o desejo do visitante de descobrir. ${ }^{10}$

Os saberes da experiência foram bastante enfatizados nos processos de formação de mediadores analisados. Esse fato foi constatado através dos seguintes fatores: o exercício da mediação foi considerado elemento importante na formação; houve participação de mediadores experientes na formação dos novatos, e ocorreu compartilhamento de experiências anteriores de mediação, ao longo dos cursos observados.

Nos dois museus, a formação em serviço foi considerada fundamental, devido às limitações dos cursos iniciais e da valorização da prática como aspecto formativo essencial. Entende-se que os saberes que fundamentam o trabalho de um mediador são também adquiridos em exercício e ao longo do tempo. Corroborando essa ideia, os entrevistados do ECV e MAST afirmam respectivamente que:

Por uma questão de limitação é um curso condensado (Curso de capacitação de mediadores para atuação em ambientes de ensino não formal) [...]. Então eu diria (que seu objetivo é): iniciar um processo [...]. E acreditar que eles vão continuar com esse processo de aprendizagem, de amadurecimento em exercício, atuando. (Vice-presidente do ECV, 28/08/2012) 
Isso é paulatino. [...] a gente observa nesse trabalho de mediação verdadeiras transformações. Por exemplo, há mediadores que já são intrinsecamente extrovertidos. Há outros que não [...] e o tempo vai passando e essa pessoa vai se “empoderando" até se sentir à vontade. Isso pode levar mais tempo ou menos tempo. Então [...] é preciso haver uma sensibilidade para respeitar esses tempos (Chefe da Coordenação de Educação do MAST, 13/12/2012)

Para Tardif (2010, p. 49), os saberes da experiência, que devem ser um dos fundamentos da formação de professores, são saberes de natureza prática: "não provêm das instituições de formação nem dos currículos, [...] não se encontram sistematizados em doutrinas ou teorias. São saberes práticos (e não da prática) [...] se integram a ela e dela são partes constituintes".

$\mathrm{O}$ autor afirma que os saberes da experiência não são acumulados apenas individualmente, mas são compartilhadas por meio da experiência coletiva. E que somente a partir desse compartilhamento é possível criar mecanismos para sistematização e objetivação desses saberes, por meio do relacionamento entre jovens professores e os mais experientes em cursos de formação de docentes, por exemplo.

Os mediadores dos museus em questão têm um papel protagonista na formação dos novatos, assim como na concepção e avaliação das atividades voltadas para o público. No curso de mediadores do ECV, das 11 atividades observadas, seis foram conduzidas exclusivamente por mediadores mais experientes. $\mathrm{E}$ no MAST, em sete de 14 atividades, ocorreu o mesmo.A presença de mediadores experientes na condução de diversas atividades possibilitou o compartilhamento de estratégias de mediação e outras experiências prévias, como a seguir:

\footnotetext{
Mas a ideia é essa. Na verdade, você tem que trazer perguntas. Porque isso está acontecendo? O que você está observando aqui? O que acontece com a luz? [...] eu sugiro a vocês que primeiro passem pelo prisma pra depois vir para cá. [...] é legal fazer essa comparação de um com outro $\left[\ldots . . .{ }^{11}\right.$

O primeiro espaço expositivo que a gente visita é o Sistema Solar em escala [...]. Durante essa prática, eu pergunto qual é o planeta mais quente do Sistema Solar. E a professora se adiantou e falou -'Mercúrio'. E não é, é Vênus. O que fazer? ${ }^{12}$
}

De maneira mais abrangente, o diálogo entre os pares mantém-se como uma estratégia permanente de formação nos museus em questão, com mediadores mais antigos supervisionando e apoiando a atuação dos mais novos constantemente.

\section{Concepções de mediadores a respeito de sua formação}

A presente pesquisa analisou concepções dos mediadores a respeito de sua formação, buscando entender que fatores contribuem para ela e que saberes são associados a ela. A primeira questão proposta no questionário foi: "De que forma você desenvolveu as habilidades necessárias ao seu trabalho como mediador?”. 
No caso do ECV, a grande maioria (27 de 31) afirma que desenvolve as habilidades necessárias à mediação durante a sua prática e, além disso, a troca de experiências entre mediadores foi citada especificamente por alguns (8). Isso reflete uma grande valorização dos saberes da experiência, como ilustrado nos depoimentos: "O curso apenas forneceu conhecimentos teóricos, já na prática é bem diferente, pois você lida com públicos diferentes a cada momento" (Mediador 14 - MAST, 09/2012). "Eles (os mediadores experientes) têm muitas experiências a nos contar e muitas informações de um 'mundo' que, até então, me era desconhecido" (Mediador 9 - ECV, 10/2012).

Além dos fatores acima, também foram mencionados: capacitações oferecidas pelo museu (8), o estudo (3), a formação acadêmica prévia (2) e cursos e palestras em outras instituições (1).

Assim como no ECV, no MAST, os mediadores deram importância aos saberes da experiência, embora tenham evidenciado também o caráter múltiplo de sua formação. Dez mediadores (de um total de 17) relacionaram o desenvolvimento de suas habilidades para o trabalho às próprias experiências de mediação com o público, e 11 citaram a relação com os mediadores mais experientes. Dois outros fatores também tiverem ocorrência significativa: o estudo individual ou em grupo (11) e a realização de cursos e palestras (8). A formação acadêmica prévia foi citada duas vezes.

Frequentemente, os mediadores do MAST citaram diversos fatores em conjunto identificando a presença de diferentes tipos de saberes em sua formação: "Com a prática e posteriormente lendo artigos, assim pude compreender melhor a função do mediador [...] e melhorar o atendimento" (Mediador 8 - MAST, 09/2012).“Através da leitura de livros sobre o desenvolvimento do Museu e a parte Astronômica. [...] através de palestras em educação não formal. E com a experiência como estudante de Licenciatura" (Mediador 11 - MAST, 09/2012).

$\mathrm{Na}$ concepção dos mediadores do ECV e do MAST, sua formação tem diferentes dimensões, incluindo ações promovidas pelos museus, como cursos e palestras, e iniciativas dos próprios mediadores, como o estudo. Muitos mediadores consideram que desenvolveram as habilidades necessárias ao seu trabalho no cotidiano, em contato com o público.

Os mediadores em questão entendem que a sua formação provém de diversas fontes, o que se relaciona à própria característica multifacetada dessa atividade. É possível fazer aproximações dessa conclusão com as ideias de Tardif (2010), para quem o saber dos professores é plural e heterogêneo por ser composto de conhecimentos e saber-fazer com várias naturezas e origens; por ser pautado em diferentes teorias, concepções e técnicas e por atender a demandas de uma prática heterogênea.

Entre as diversas facetas de sua formação, a troca de experiência entre os pares foi bastante citada pelos mediadores do ECV e do MAST. A seguinte questão possibilitou um entendimento mais detalhado desse aspecto: “O diálogo com mediadores mais experientes contribui para seu trabalho como mediador? Por quê?".

No caso do ECV, apenas um dos mediadores não considerou esse diálo- 
go importante, e todos os mediadores do MAST concordam que a troca de experiências é essencial em sua formação. Alguns não especificaram por que, mas oito do ECV e sete do MAST ressaltam que ocorre nos museus um importante compartilhamento de estratégias de mediação: "Porque os mediadores mais experientes têm muitas histórias para contar, sobre perguntas já ouvidas [...], sobre modos diferentes de mediar um mesmo módulo. Sempre podemos aprender com quem tem mais experiência" (Mediador 29 - ECV, 10/2012).

A colaboração entre mediadores, portanto, mostrou-se pertinente, como já observado por Silva (2009) a respeito das concepções dos mediadores do Centro de Ciências de Araraquara sobre a sua formação:

Esse tipo de troca e compartilhamento de saberes é recorrente [...]. Nossos sujeitos de pesquisa demonstraram compartilhar "macetes"; modos de fazer; modos de organizar os visitantes; de apresentar os equipamentos frequentemente. O diálogo entre os monitores, veteranos e novatos, entre novatos e novatos, já faz parte do contexto profissional desses sujeitos e contribuem para o aprimoramento de todos os envolvidos. (SILVA, 2009, p. 108)

Tardif (2010) considera a troca de experiências um dos pilares da formação de professores. Não há dúvida a respeito da relevância da prática e da troca de experiências também para a formação de mediadores, que convivem em seu trabalho com imprevisibilidades as quais devem superar por meio da criatividade e da reflexão na ação (MARANDINO, 2008a). Assim, na sua formação deve ser considerado o desenvolvimento de um pensamento prático que "não pode ser ensinado, mas pode ser aprendido através de uma reflexão conjunta de novos atores que surgem na interface entre a formação e a profissão: futuros mediadores e profissionais com maior experiência [...]" (QUEIROZ, 2002, p. 80).

É importante ressaltar, no entanto, que o compartilhamento de experiências aliada à formação em serviço pode ser a principal estratégia de formação de mediadores nas instituições em questão. O que possivelmente se dá em resposta também a uma falta de capacidade operacional desses museus em desempenhar essa tarefa de forma mais integral e sistemática. Alguns mediadores do MAST expuseram claramente essa lacuna: "No meu caso, a maior parte do [...] aprendizado aconteceu acompanhando o trabalho de mediadores mais experientes. Isso aconteceu porque, na época que entrei, não houve a capacitação de mediadores" (Mediador 7 - MAST, 09/2012).

No Espaço Ciência Viva, esse assunto também foi mencionado:

[...] a ausência de uma [...] capacitação para os bolsistas durante o ano, o que só ocorre no início do ano, fez com que seja quase que obrigatória uma capacitação informal através do contato com mediadores mais experientes, em especial [...] na observação de seu trabalho durante a visita de escolas (Mediador 17 - ECV, 10/2012).

Levando em conta o perfil dos mediadores em questão, em grande parte estudantes e sem experiência prévia, compreende-se que é necessário um acompanhamento de seu trabalho e uma atenção à sua formação que vá além de mo- 
delos centrados na prática e relação aprendiz-mestre (MARANDINO, 2008b).

Os mediadores ingressam no museu com uma bagagem teórica e prática advinda de sua formação acadêmica na graduação e no Ensino Médio que seguramente será integrada ao repertório de saberes que mobilizam em seu trabalho.

[...] os mediadores de museus recém-chegados à educação não formal tendem, naturalmente, a aplicar os conhecimentos, disciplinares e pedagógicos, trazidos da formação universitária, uma vez que não existe uma formação própria que os preparem para atuar (em museus) (SOARES, 2003, p. 84).

Esse fator também foi considerado, por meio da questão "O que você aprendeu na faculdade (ou no Ensino Médio) contribui para o seu trabalho como mediador? Por quê?".

Dos 31 mediadores do ECV, 27 reconhecem essa contribuição e dos 17 do MAST, 14 concordam. Alguns justificaram a resposta relacionando a contribuição da formação acadêmica prévia à aquisição de: conhecimentos teóricos e práticos em educação (10 do ECV e 3 do MAST) e conhecimentos teóricos das ciências de referência abordadas no museu ( 7 do ECV e 3 do MAST $)^{13}$. Ou seja, os mediadores relacionam sua formação acadêmica à obtenção de saberes da formação profissional, da experiência e disciplinares, como relatado a seguir: "Meu conhecimento científico, principalmente na área da química, me ajudou a entender sobre astronomia, que era uma área desconhecida por mim. E o meu conhecimento em educação me ajudou bastante com o contato com o público" (Mediador 7 - MAST, 09/2012). "Porque na formação de professores fazemos estágio, é parecido com trabalhar como mediador" (Mediador 26 ECV,10/2012) ${ }^{14}$.

Diferentes saberes adquiridos na graduação foram valorizados por mediadores do ECV e do MAST, corroborando o observado por Ovigli e Freitas (2009), a respeito de mediadores do Centro de Divulgação Científica e Cultural da Universidade de São Paulo:

[...] quanto à interface graduação/atuação no museu, as [...] monitoras concordam que os conteúdos específicos estudados durante a graduação contribuíram para sua atuação no centro de ciências, sendo para elas fundamental conhecer bem os conceitos científicos presentes na exposição. [...] competências comunicativas, segundo as monitoras, puderam ser desenvolvidas parcialmente durante a graduação, em disciplinas que incluíam a realização de seminários e outras apresentações orais, em especial nas disciplinas pedagógicas. (OVIGLI; FREITAS, 2009, p. 702)

A formação acadêmica prévia desempenha, portanto, um papel importante na formação de mediadores, como verificado por outros autores (SOARES, 2003; ALENCAR, 2008; OVIGLI, 2009). Considera-se que, do ponto de vista dos espaços de educação não formal, o estabelecimento de parcerias com instituições de formação de professores é uma questão premente para uma melhor qualificação dos profissionais que atuam na área. 


\section{CONSIDERACְ̃̃ES FINAIS}

A formação de mediadores nos museus em questão não ocorreu apenas a partir de ações organizadas e desempenhadas por essas instituições, mas envolveram saberes disciplinares, da formação profissional e da experiência, todos essenciais a uma boa prática.

Entende-se que a mediação é uma atividade complexa, influenciada por múltiplos fatores e desempenhada muitas vezes por profissionais em formação. Por conseguinte, a capacitação de mediadores para o trabalho demanda tempo, investimento permanente e deve abarcar distintas estratégias metodológicas e áreas do conhecimento.

Em ambos os museus observados, a formação em serviço e a troca de experiências foram consideradas elementos essenciais na formação de mediadores. É importante questionar se esse fato foi influenciado por limitações de tempo, orçamentárias ou outras, ou se representa verdadeiramente uma escolha por parte das instituições analisadas.

Como observado, as ações de formação em serviço foram realizadas de maneira informal, sem um planejamento detalhado e com um caráter não obrigatório. Não fica claro se todos os mediadores tiveram a oportunidade de participar dessas ações e se atendiam plenamente às suas necessidades de formação.Foi exposto por alguns mediadoresque a observação dos mais experientes foi um dos principais ou até únicos recursos para a sua formação. Devido à grande rotatividade nas equipes, nem todos participaram de cursos de formação de mediadores.

Foram identificados nos processos estudados diferentes abordagens referentes aos saberes disciplinares. No ECV houve maior ênfase ao longo do curso de mediadores.No MAST, estes foram tratados de maneira menos aprofundada, estando mais presentes apenas durante ações de formação em serviço. Neste museu foram priorizados os saberes da formação profissional, compreendidos aqui como as teorias provenientes do campo da educação em museus que embasam as práticas de mediação.

Abordar os saberes pedagógicos na formação de mediadores significa estabelecer uma relação entre a pesquisa acadêmica e a prática na área de educação em museus. A formação de mediadores, nesse contexto, passa a não se basear apenas na experiência adquirida dentro das próprias instituições, mas pode incorporar outras referências, sendo ampliado o olhar sobre as práticas de mediação realizadas.

Dada a ênfase nos saberes da experiência, propõe-se que seja interessante que os museus proporcionem espaços propícios para a troca de conhecimentos teóricos e práticos entre esses profissionais. Nesse sentido, o registro das atividades educativas e das práticas de mediação também é primordial, pois representa uma formalização da experiência adquirida, permitindo o seu compartilhamento. Valorizar os saberes da experiência construídos pelos mediadores significa ainda os incluir na concepção de atividades educativas e exposições.

A presente pesquisa procurou colaborar para o desenvolvimento de um escopo teórico que embase a formação de mediadores em museus de ciência, o que é considerado fundamental para o aperfeiçoamento desses processos e para o entendimento de suas especificidades. 


\section{NOTAS}

${ }^{1}$ As informações a respeito do acervo do MAST e de sua organização administrativa foram consultadas em <www.mast.br>.

${ }^{2}$ Foram considerados para análise dos processos de formação de mediadores nos museus em questão dois tipos de ações, as de formação inicial e as de formação em serviço, entendidas no âmbito desta pesquisa respectivamente como: ações realizadas pelos museus antes e ações realizadas pelos museus depois de o mediador começar a trabalhar com o público nesses espaços.

${ }^{3}$ ECV - Coordenação de Aperfeiçoamento de Pessoal do Nível Superior (CAPES); Programa Institucional de bolsas de extensão da Universidade Federal do Rio de Janeiro (PIBEX/UFRJ); Programa de bolsas-auxílio para Atividades Discentes da Universidade Estadual do Rio de Janeiro (UERJ)/ Escola Municipal Julia Kubitschek. MAST - Conselho Nacional de Desenvolvimento Científico e Tecnológico (CNPq): Programa Institucional de Bolsas de Iniciação Científica para o Ensino Médio (PIBIC-EM); Programa Institucional de Bolsas de Iniciação Científica (PIBIC) e Programa de Capacitação Institucional (PCI)/ Centro de Integração Empresa-Escola (CIEE).

${ }^{4}$ Parceria com a Escola Municipal Julia Kubitschek, cujos alunos de formação à docência realizam estágios curriculares no museu.

${ }^{5}$ Curso ECV - Na atividade "Ciência e Arte”, durante apresentação de vídeo, 26/03/2012.

'Trecho retirado da programação do curso "Mediação em museus e centros de ciência: teoria e prática".

${ }^{7}$ Curso MAST-Durante a atividade "Saberes da Mediação”, 25/01/2012.

${ }^{8}$ Programa Institucional de Bolsas de Iniciação Científica para o Ensino Médio (PIBIC-EM); Programa Institucional de Bolsas de Iniciação Científica (PIBIC) e Programa de Capacitação Institucional (PCI).

${ }^{9}$ CURSO MAST -Durante a atividade “Trilhas educativas do MAST”, 24/01/2012.

${ }^{10}$ CURSO ECV, na atividade “Abertura do Curso”, 19/03/2012.

${ }^{11}$ Curso ECV - Na atividade "Física nas Cores", durante apresentação de experimentos na "Sala Escura", 27/03/2012.

${ }^{12}$ Curso MAST - Durante a atividade "Mediação segundo os mediadores”, 26/01/2012.

${ }^{13}$ Três mediadores do MAST ainda mencionaram o conhecimento sobre outros temas como: a divulgação, a história e a filosofia da ciência.

${ }^{14} \mathrm{O}$ mediador 7 era estudante de graduação em Química, e o mediador 26 era estudante de Ensino Médio da Escola Municipal Julia Kubitschek. 


\section{REFERÊNCIAS}

ALENCAR, V. O mediador cultural: considerações sobre a formação e profissionalização de educadores de exposições e museus de arte. 2008. 108 f. Dissertação (Mestrado) - Universidade Estadual Paulista, Instituto de Artes, São Paulo, 2008.

ALMEIDA, P.; BIAJONE, J. Saberes docentes e formação inicial de professores: implicações e desafios para as propostasde formação. Educação e Pesquisa, São Paulo, v. 33, n. 2, p. 281-295, 2007.

ALVES-MAZZOTTI, A.; GEWANDSZNAJDER, F. O método nas ciências naturais e sociais: pesquisas quantitativa e qualitativa. 2. ed. São Paulo: Pioneira Thomson Learning, 1999. 203 p.

AZEVEDO, M. do R. Mediação cultural na contemporaneidade: os museus.2003.154 f. Dissertação (Mestrado) - Universidade Lusófona de Humanidades e Tecnologia, Lisboa, 2003.

BOGDAN, R.; BICKLEN, S.Qualitative research for education: An introduction to theory and methods.Boston: Alyn and Bacon, 1982. 253 p.

BORGES, C.; TARDIF, M. Dossiê: Os saberes docentes e sua formação. Educação e Sociedade, Campinas: Cedes, v. 22, n. 74, p. 11-26, 2001.

BRITO, F. Experimentando a mediação: desafio constante. In: MASSARANI, L. (Ed.) Workshop sul americano e Escola de mediação em Museus e Centros de Ciências.Rio de Janeiro: Museu da Vida/ Casa de Oswaldo Cruz/ Fiocruz, 2008. p. 37- 42.

BRUNO, M. C. (Org.). A memória do pensamento museológico contemporâneo: documentos e depoimentos. São Paulo: Comitê Brasileiro do Conselho Internacional de Museus (ICOM), 1995.

CAFFAGNI, C. W. O estudo das analogias como recurso didático por monitores em um centro de ciência e tecnologia de São Paulo-SP. 2010. 207 f. Dissertação (Mestrado) - Faculdade de Educação da Universidade de São Paulo, São Paulo, 2010.

CAZELLI, S.; COIMBRA, C. A. Avaliar as ações educativas em museus: como, para quê e por quê? In: ENCONTRO NACIONAL DA REDE DE EDUCADORES EM MUSEUS E CENTROS CULTURAIS DO ESTADO DO RIO DE JANEIRO, v. 1, 2007, Rio de Janeiro, RJ. Anais... Rio de Janeiro: Fundação Casa de Rui Barbosa, 2010. p. 165-187.

COUTINHO-SILVA, R.; PERSECHINI, P.; MASUDA, M.; KURTENBACH, E. Interação museu de ciências-universidade: contribuições para o ensino não-formal de ciências. Ciência e Cultura, São Paulo, v. 57 , n. 4 , 2005, p. 24-25.

DAVALLON, J. A mediação: a comunicação em processo? Revista virtual Prisma de Ciências da Informação e Comunicação, n. 4, p. 3-36. jun. 2007. Disponível em: <http://prisma.cetac.up.pt/ edicao_n4_junho_de_2007>. Acesso em: 5 abr. 2012.

JACOMY, B. Instrumentos, máquinas e aparatos interativos de ciência e tecnologia exibidos nos museus. In: VALENTE, M. E. (Org.) Museus de Ciência e Tecnologia - interpretações e ações dirigidas ao público (Museums of Science and Technology - interpretations and activities to the public). Rio de Janeiro: Museu de Astronomia e Ciências Afins, 2007. p. 15-24.

LUDKE, M.;ANDRE, M. Pesquisa em educação: abordagens qualitativas. São Paulo: EPU, 1986. $99 \mathrm{p}$.

MARANDINO, M. Perspectivas da pesquisa educacional em museus de ciências. In: SANTOS, F. M.; GRECA, I. M. A pesquisa em ensino de ciências no Brasil e suas metodologias. Ijuí: Unijuí, 2006. p. 89-122.

MARANDINO, M. (Org). Educação em museus: a mediação em foco.São Paulo: Grupo de Estudo e Pesquisa em Educação Não Formal e Divulgação da Ciência/ Universidade de São Paulo/ Faculdade de Educação, 2008a. 48 p. 
MARANDINO, M. Ação educativa, aprendizagem e mediação nas visitas aos museus de ciências. In: MASSARANI, L. (Ed.) Workshop sul americano e Escola de mediação em Museus e Centros de Ciências. Rio de Janeiro: Museu da Vida/ Casa de Oswaldo Cruz/ Fiocruz, 2008b. p. 21-28.

MARTINS, L. A constituição da educação em museus: o funcionamento do dispositivo pedagógico museal por meio de um estudo comparativo entre museus de artes plásticas, ciências humanas e ciência e tecnologia. 2011. 390 f. Tese (Doutorado) - Universidade de São Paulo, Faculdade de Educação, São Paulo, 2011.

MASSARANI, L.; MERZAGORA, M.; RODARI, P. (Org.)Diálogos e ciência: mediação em museus e centros de ciências. Rio de Janeiro: Museu da Vida/ Casa de Oswaldo Cruz/ Fiocruz, 2007. 92 p. MINAYO, M. C. (Org.); DESLANDES, S.; NETO, O.; GOMES, R. Pesquisa social: teoria, método e criatividade. 21. ed. Petrópolis, RJ: Vozes, 1999.80 p.

MORAES, R.; BERTOLETTI, J.; BERTOLETTI, A. C.; ALMEIDA, L. de. In: MASSARANI, L.; MERZAGORA, M.; RODARI, P. (Org.) Diálogos e ciência: mediação em museus e centros de ciências.Rio de Janeiro: Museu da Vida/ Casa de Oswaldo Cruz/ Fiocruz, 2007. p. 55-66.

MUSEU DE ASTRONOMIA E CIÊNCIAS AFINS. Plano diretor, 2011-2015: planejamento estratégico do MAST. Rio de Janeiro, 2010, 25 p.

NASCIMENTO, S.; VENTURA, P. C. A dimensão comunicativa de uma exposição de objetos técnicos. Ciência e Educação, Bauru, v. 11, n. 3, p. 445-455, 2005.

OVIGLI, D. Os saberes da mediação humana em centros de ciências: contribuições para a formação inicial de professores. 2009. 228 f. Dissertação (Mestrado) - Universidade Federal de São Carlos, São Carlos, 2009.

OVIGLI, D.; FREITAS, D. Contribuições de um centro de ciências para a formação inicial do professor. In: I SIMPÓSIO NACIONAL DE ENSINO DE CIÊNCIA E TECNOLOGIA. Anais... Paraná: Universidade Tecnológica Federal do Paraná, 2009. p. 693-708.

QUIVY, R.; CAMPENHOUDT, L. V. Manual de investigação em ciências sociais. 5. ed. Lisboa: Graduva, 2008. 282 p.

QUEIROZ, G.; KRAPAS, S.; VALENTE, E.; DAVID, É.; DAMAS, E.; FREIRE, F. Construindo saberes da mediação na educação em museus de ciência: o caso dos mediadores do Museu de Astronomia e Ciências Afins. Revista Brasileira de Pesquisa em Educação em Ciências, v. 2, n. 2, p. 77-88, 2002.

RIBEIRO, M. das G.; FRUCCHI, G. Mediação - a linguagem humana dos museus. In: MASSARANI, L.; MERZAGORA, M.; RODARI, P. (Org.) Diálogos e ciência: mediação em museus e centros de ciências. Rio de Janeiro: Museu da Vida/ Casa de Oswaldo Cruz/ Fiocruz, 2007. p. 67-74.

RODARI, P.; MERZAGORA, M. Mediadores em museus e centros de ciência: Status, papéis e treinamento. Uma visão geral européia. In: MASSARANI, L.; MERZAGORA, M.; RODARI, P. (Org.). Diálogos e ciência: mediação em museus e centros de ciências. Rio de Janeiro: Museu da Vida/ Casa de Oswaldo Cruz/ Fiocruz, 2007. p. 7-20.

SILVA, C. Formação e atuação de monitores de visitas escolares de um centro de ciências: saberes e prática reflexiva.2009. 141 f. Dissertação (Mestrado) - Universidade Estadual Paulista, Bauru, São Paulo, 2009.

SOARES, B. O reencontro com o humano no museu contemporâneo.2008. 152 f. Dissertação (Mestrado) - Universidade Federal do Estado do Rio de Janeiro / Museu de Astronomia e Ciências Afins, Programa de Pós-graduação em Museologia e Patrimônio, Rio de Janeiro, 2008.

SOARES, J. M. Saberes da mediação humana em museus de ciência e tecnologia. 2003. 115 f. Dissertação (Mestrado) - Universidade Federal Fluminense, Niterói, 2003.

TARDIF, M. Saberes docentes e formação profissional.10. ed. Petrópolis, RJ: Vozes, 2010. 325p. 
VALENTE, M. E. Educação em museu: o público de hoje no museu de ontem.1995. 208 f. Dissertação (Mestrado) - Pontifícia Universidade Católica, Departamento de Educação, Rio de Janeiro, 1995. VALENTE, M. E. Museus de Ciências e Tecnologia no Brasil: uma história da museologia entre as décadas de 1950-1970.2008. 276 f. Tese (Doutorado) - Universidade Estadual de Campinas, Instituto de Geociências, Pós-graduação em Ensino de História e Ciências da Terra, Campinas, 2008.

VALENTE, M. E. Educação em museus: a dimensão educativa do museu. In: GRANATO, M.; SANTOS, C. dos; LOUREIRO, M. L. (Org.). Museu e Museologia: interfaces e perspectivas. v. 11.Rio de Janeiro: Museu de Astronomia e Ciências Afins, 2009. p. 83-98.

Data de envio: 05/11/2014

Data de aprovação: 28/01/2016

Data da versão final: 17/02/2016

\section{Contato:}

Izabel Lourenço Gomes

Rua General Bruce, 586

Bairro Imperial de São Cristovão - Rio de Janeiro

CEP: 20.921-030

isabelgomes@mast.br 